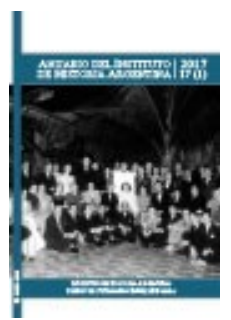

Anuario del Instituto de Historia Argentina, vol. 17, nº 1, e042, junio 2017.

ISSN 2314-257X

Universidad Nacional de La Plata.

Facultad de Humanidades y Ciencias de la Educación.

Centro de Historia Argentina y Americana

\title{
Política, deporte y diplomacia cultural: la Nueva Argentina de Perón y los Juegos Panamericanos de $1951^{1}$
}

\author{
Politics, Sports and Cultural Diplomacy: The New Argentina of \\ Perón and the Pan-American Games of 1951
}

\section{Raanan Rein *}

* Universidad de Tel Aviv, Israel | raanan@post.tau.ac.il

\section{PALABRAS CLAVE}

Peronismo

Populismo

Deporte

Juegos Pan-Americanos

Mundo Deportivo

KEYWORDS

Peronism

Populism

Sports

Pan-American Games

Mundo Deportivo

\section{RESUMEN}

El régimen peronista alentó y financió una amplia variedad de actividades deportivas. Esta inversión rindió sus frutos también en el extranjero y Perón intentó capitalizar los logros de atletas individuales, así como de seleccionados nacionales en competencias internacionales. Los logros eran presentados como una victoria colectiva de la sociedad argentina. La participación argentina en los Juegos Olímpicos de Londres (1948), el campeonato mundial de básquetbol que se celebró en Buenos Aires en 1950 y sobre todo los primeros Juegos Panamericanos del año siguiente promovían el patriotismo y la unidad nacional en el frente doméstico y servían como diplomacia cultural para mejorar la imagen del país allende las fronteras. Este artículo ofrece una lectura minuciosa del suplemento de 250 páginas que publicó el periódico Mundo Deportivo, auspiciado por las autoridades nacionales, a la semana siguiente de la clausura de los juegos.

\section{ABSTRACT}

The Peronist regime encouraged and financed a wide variety of sports activities. This investment bore fruit internationally and Perón tried to make political capital out of the achievements of Argentine individual athletes or national teams in international competitions. Such achievements were presented as a collective victory of Argentine society. Argentine participation in the London Olympics in 1948, the hosting of the world basketball championship in Buenos Aires in 1950, and above all the organization of the first Pan-American games in the Argentine in April 1951, all served to promote patriotism and national unity at home and improve the country's image in the international scene. This paper analyzes the 250 page book published by the sports magazine Mundo Deportivo at the end the Games. 


\section{Introducción}

Con 153 medallas en su haber, 68 de ellas de oro”, el régimen de Juan D. Perón bien podía celebrar una importante victoria en marzo de 1951. Desde el punto de vista deportivo pero también desde el político y el diplomático, la gigantesca inversión en la organización de los Juegos Panamericanos (del 25 de febrero al 8 de marzo de aquel año) demostró ser lucrativa. Veintidós delegaciones con más de 2500 atletas compitieron en 18 disciplinas y atrajeron la atención de millones de seguidores de todo el continente (Rodríguez, 2011). El hecho de que la Argentina ganara más medallas que cualquier otra nación americana y que los Estados Unidos llegaran solo al segundo puesto, con 95 medallas, fue otra de las razones para festejar² ${ }^{2}$. Con toda claridad, la competición demostró, dentro y fuera de la República Argentina, el grado de importancia que el gobierno asignaba a los deportes y a su posible uso para promover determinados valores, imágenes y mensajes.

Durante el régimen peronista (1946-1955), el gobierno argentino alentó y financió una amplia variedad de actividades deportivas. Fueron promovidos tanto disciplinas de aficionados como de profesionales, para niños y para adultos, para hombres y para mujeres, y no sólo en la Capital Federal, sino también en las provincias y los territorios nacionales. Sin duda, ningún gobierno antes del de Perón había invertido tantas energías y recursos en el desarrollo y fomento de actividades atléticas y competitivas, ni se había esforzado tanto en cosechar dividendos de esta política. Esta expansión de los deportes fue una expresión del carácter populista del régimen (Rein, 2013) y de la rehabilitación de diferentes facetas de la cultura popular (Rein, 1998; Fernández Moores, 2010; Senén González, 1996). Esta inversión rindió sus frutos también en el extranjero y Juan Perón intentó capitalizar los logros de atletas individuales, como el campeón mundial de automovilismo Juan Manuel Fangio y el boxeador Pascual Pérez, así como del boxeador e ídolo deportivo José María Gatica, o de seleccionados nacionales en competencias internacionales. Los logros eran presentados como una victoria colectiva de la sociedad argentina, y trascendían las divisiones de clases sociales, orígenes étnicos, sitios de residencia o filiaciones políticas. La participación argentina en torneos internacionales promovía el patriotismo y la unidad nacional en el frente doméstico y servía como diplomacia cultural para mejorar la imagen del país allende las fronteras (Torres, 2014).

Tras un breve relato del proceso que condujo a la celebración de los primeros Juegos Panamericanos, este artículo propone una nueva mirada sobre los juegos y su papel a la hora de afianzar el apoyo para el gobierno peronista y de elaborar una diplomacia cultural destinada a mejorar la imagen internacional del justicialismo. Al mismo tiempo, el artículo ofrece una lectura minuciosa del suplemento de 250 páginas que publicó el periódico Mundo Deportivo -auspiciado por las autoridades nacionales- durante la semana posterior a la clausura de los juegos. $\underline{3}$ Dicho folleto facilita una lente adicional para analizar la visión que tenía el régimen sobre el lugar del deporte en la sociedad argentina y sobre el liderazgo que podría ejercer el país en la escena continental. Tanto el texto como las imágenes contenidas en el suplemento dan testimonio de la índole populista de Perón, de su búsqueda de modernización, del hincapié puesto en la movilidad social y de la imposición autoritaria de un ideal de unidad nacional.

El contexto continental es importante para comprender mejor la imagen que el gobierno argentino trataba de impulsar en las Américas. Por aquel entonces, el régimen peronista invertía grandes esfuerzos en demostrar que el país pretendía establecer una política exterior genuinamente independiente que no estuviera sujeta a injerencias foráneas. En lo económico y lo social, la Argentina manifestaba su opción por una tercera posición, una alternativa tanto al capitalismo (o individualismo) como al comunismo (o colectivismo). Esto se reflejaba también en su política exterior con una actitud que se distanciaba tanto de la política de los Estados Unidos (capitalismo imperialista) como de la de la U.R.S.S. (comunismo no menos imperialista). La 
Tercera Posición -sostenían los teóricos de la doctrina peronista- no era un mero mensaje carente de significado práctico, sino la plataforma ideológica que serviría a los intereses nacionales en sus relaciones con otros países. En la segunda mitad de la década de 1940, el manejo de los asuntos argentinos con la España franquista y con Palestina sirve como ejemplo de una política exterior supuestamente independiente en un contexto de Guerra Fría en escalada y un sistema internacional bipolar.

De hecho, Perón y sus ministros de Relaciones Exteriores y de Defensa dijeron reiteradamente a diplomáticos estadounidenses que la Tercera Posición no era más que "un poco de demagogia para consumo interno” (Rein, 1998:165) y que no significaba que, en caso de conflicto entre el bloque occidental y el oriental, la Argentina mantendría la neutralidad. En agosto de 1946, dos meses después de haber asumido el poder, el presidente argentino ya había declarado públicamente que su país era parte del continente americano y que conforme a ello se sumaría a los Estados Unidos y a los demás países de la región en un conflicto futuro, y que en caso de estallar una contienda entre los Estados Unidos y la Unión Soviética, la Argentina estaría del lado de los primeros (Rein, 1993:114).

Pese a la reputación de Perón como anti-yanqui al acceder al poder, muy pronto comenzó a propiciar un acercamiento con los Estados Unidos, con la esperanza de importar maquinaria, tecnología y materias primas vitales para el programa de industrialización que deseaba implementar, así como armamento moderno para reemplazar los equipos anticuados utilizados por las diferentes ramas de las fuerzas armadas argentinas. Por consiguiente, a pesar de toda su retórica acerca de sus políticas independientes, la Argentina ratificó con celeridad el Acta de Chapultepec y la Carta de San Francisco. No obstante todo esto, los oficiales estadounidenses continuaron abrigando sospechas sobre Perón y sus intenciones, tanto en la Argentina como en los países vecinos. Los Juegos Panamericanos - esperaban en el gobierno peronista- mejorarían la imagen argentina en Estados Unidos.

En este artículo empleo los conceptos de populismo y régimen al referirnos a los dos primeros gobiernos peronistas. Populismo es uno de los términos más confusos en el léxico político moderno. A partir de un liderazgo carismático, el populismo ofrecía una vía reformista intermedia en la que se enfatizaba el principio estatista; es decir, daba preeminencia al Estado en las cuestiones sociales y económicas para evitar distorsiones y garantizar el progreso, aunque sin propósito alguno de cuestionar el principio capitalista de propiedad privada. El nacionalismo ha sido un componente central del discurso populista, al igual que lo ha sido una cierta dosis de retórica antiimperialista y la búsqueda de un mayor margen de independencia económica. Al mismo tiempo, el populismo prometía solidaridad social para hacer frente a la alienación de las capas bajas dentro del contexto del capitalismo industrial moderno, particularmente entre los migrantes llegados del interior del país a las grandes ciudades. Además de dignificar distintos aspectos del trabajo y la vida de los trabajadores, los gobiernos populistas se esforzaban en rehabilitar diversos aspectos de la cultura popular y del folklore que hasta entonces habían sido despreciados por las elites orientadas culturalmente hacia Europa. En otras palabras, planteaban una nueva jerarquía del orden simbólico de la sociedad.

Uso el concepto de régimen para destacar que no se trataba de otro gobierno de turno sino de nuevas autoridades que bregaban por desligarse de los patrones políticos, ideológicos, sociales y económicos que una oligarquía estrecha había impuesto a la Argentina durante décadas. Una condición necesaria para cumplir estos objetivos era la modelación de una nueva conciencia nacional, que garantizara a largo plazo el apoyo popular al movimiento peronista, más allá del entusiasmo inicial, momentáneo y espontáneo. Por lo tanto, se promovió -entre otras políticas y medidas- la reforma constitucional, así como nuevas políticas en las áreas de educación y deporte. 


\section{De los Juegos Olímpicos en Londres a los Juegos Panamericanos en Buenos Aires}

La escena de los deportes internacionales ofreció una serie de oportunidades a la Argentina peronista para destacar un nuevo capítulo en su historia competitiva. Algunos hitos clave incluyen los Juegos Olímpicos de Londres (1948) y Helsinki (1952), una candidatura que no prosperó para hospedar la olimpiada en 1956, el campeonato mundial de básquetbol que se celebró en Buenos Aires en 1950 y los primeros Juegos Panamericanos el año subsiguiente. En todos estos encuentros, los atletas argentinos representaban supuestamente los logros del régimen mediante una serie de imágenes y de liturgia partidaria. El hospedaje de eventos deportivos internacionales ofrecía una plataforma para exhibir la índole transformadora del peronismo que presuntamente colocaba al país en la senda hacia la grandeza. Al fin y al cabo, como dijo Perón, los deportistas argentinos bajo la tutela del peronismo estaban construyendo la Nueva Argentina y pretendían transformarla en una gran nación (Rein, 1998). El deporte tenía el potencial para inspirar fraternidad, cooperación, solidaridad social, identidad nacional, disciplina y lealtad.

Desde fines del s. XIX y hasta la década de 1940, las actividades deportivas en Argentina fueron mayormente un esfuerzo privado desarrollado por diversas asociaciones, mientras el Estado se destacaba por su ausencia o su apatía (Frydenberg, 2011). Perón, en contraste, sistematizó la participación estatal en esta esfera y buscó establecer un sistema centralizado para la supervisión de todas las disciplinas deportivas. Aprovechó la fusión que tuvo lugar antes entre la Confederación Argentina Deportiva y el Comité Olímpico Argentino, conocido por su acrónimo combinado CADCOA (Torres, 2001). El gobierno también nombró a activistas peronistas para encabezar asociaciones y federaciones deportivas. Por ejemplo, en el caso de la Asociación del Fútbol Argentino (AFA) hubieron entre 1947 y 1955 cinco presidentes diferentes y todos ellos -desde Oscar L. Nicolini, ministro de Comunicaciones, al sindicalista Cecilio Conditti- estuvieron comprometidos con la peronización del fútbol (Rein, 2015). Desde 1948 y hasta 1955, la función de supervisión de las actividades deportivas mediante la CADCOA fue depositada en las manos de Rodolfo G. Valenzuela, el leal presidente de la Suprema Corte de Justicia. Tal como era costumbre en numerosas asociaciones deportivas y en clubes de fútbol, los Perón fueron investidos como presidentes honorarios de la CADCOA.

La delegación olímpica que partió hacia Londres en 1948 fue la más grande que había enviado el país hasta entonces. Cuando el Comité Olímpico Internacional seleccionó, en septiembre de 1946, a la capital inglesa como sede, la CADCOA comenzó los preparativos para este evento con un firme compromiso de generoso apoyo financiero del gobierno por intermedio de su ministro de Finanzas Ramón Cereijo. Este dejó claro a los presidentes de la CADCOA -Juan Carlos Palacios primero, y después a su reemplazante Ricardo Sánchez de Bustamante- que las autoridades brindarían todo el respaldo necesario para que los atletas argentinos pudieran demostrar el espíritu combativo y el prestigio del que gozaban en la arena internacional ${ }^{4}$.

El contingente -el más grande de América Latina en estos primeros Juegos Olímpicos tras la guerra mundial- contó con 365 participantes, 242 de los cuales, eran competidores. Estos atletas, eran considerados embajadores al servicio de la doctrina justicialista, como se lo dijo el propio presidente de la nación al billarista Ezequiel Navarra cuando derrotó a su adversario estadounidense William F. Hoppe en 1951 (Scher, Blanco \& Bustillo, 2010:284). El semanario deportivo El Gráfico se hizo eco de declaraciones de este tipo en su nota titulada “¡Ar-gen-ti-na!”․ㅡ. Tal como escribió César Torres: “[Perón] reconoció que como tecnología social, el deporte era también un instrumento de diplomacia” (Torres, 2014:161). Los logros obtenidos en 1948 fueron impresionantes: tres medallas de oro, tres de plata y una de bronce, en boxeo, tiro, atletismo y navegación a vela. Este logro sigue siendo el mejor desempeño argentino en un Juego Olímpico.

Cuando la delegación regresó a Buenos Aires, a mediados de diciembre se organizó un homenaje a Perón y a su esposa en el estadio del Club Atlético River Plate, uno de los sitios favoritos del régimen para este tipo de 
eventos, incluidos los Juegos Panamericanos ${ }^{6}$. En el discurso que pronunció en esa ocasión, el Presidente trazó un paralelo entre los logros de los atletas y la empresa peronista:

Sea nuestro homenaje para las glorias del deporte que nos acompañan, para los campeones, para todos los deportistas que están construyendo la Nueva Argentina que anhelamos, de hombres robustos y de hombres fuertes; porque socialmente hacen grandes a las naciones los pueblos sanos y vigorosos. ${ }^{7}$

Miembro fundador de la Fédération Internationale de Basketball (FIBA), la Argentina fue seleccionada en 1948 para albergar el primer campeonato mundial de ese deporte. El torneo, que contó con la participación de diez equipos de las Américas, Europa y Medio Oriente se jugó en Buenos Aires a finales de 1950 declarado "Año del Libertador"- para conmemorar el centenario de la muerte del General José de San Martín. El gobierno peronista hizo cuanto tuvo a su alcance para glorificar al héroe nacional con la mayor fanfarria posible. El campeonato mundial masculino de básquet encajó perfectamente en la estrategia del régimen.

La escuadra argentina, con estrellas como Óscar Furlong y Ricardo González, derrotó a Francia, Brasil, Chile y Egipto; pero su principal victoria la obtuvo contra los Estados Unidos, el otro equipo que llegó invicto al partido final. El 3 de noviembre, los albicelestes se impusieron 64-50 para deleite de los 21.000 espectadores que fueron al Luna Park y de la nación entera. La Argentina ganó una copa internacional, pero también obtuvo un resonante triunfo sobre la gran potencia imperialista del Norte. $\underline{8}$

Numerosos porteños celebraron el triunfo hasta las tres de la mañana marchando con antorchas por la céntrica avenida Corrientes. Perón felicitó al capitán del seleccionado nacional diciendo: "lo que ustedes acaban de hacer por la Argentina es mejor que el trabajo de cien embajadores” (Moores, 2010:145). Según Mundo Deportivo, el logro argentino era de tal magnitud que produjo "una revolución extraordinaria en la técnica del básquetbol”, puesto que este deporte "venía siendo desvirtuado en su propia cuna al convertírselo en una simple conquista de goles en base a la utilización de hombres de talla gigantesca, cuya misión conspiraba contra el sentido atlético y ético". El equipo argentino, en cambio, mostró “técnica, entusiasmo, método, educación colectiva y corazón”. Su victoria era “manifestación cabal de un espíritu nacional”ํ. Un comentarista que en la radio intentó argumentar que el seleccionado estadounidense no era el más fuerte que ese país podía haber presentado (la mayor parte de los jugadores eran del Denver Chevrolet, Phillips 66 y de la Universidad de Oklahoma) pagó por su opinión con su puesto de trabajo (Rein, 1998; Elsey, 2016).

En la sociedad argentina contemporánea, polarizada y dividida, los sectores críticos del régimen peronista se apresuraron a comparar, con típicas hipérboles, la organización del mundial de básquetbol en 1950 y los I Juegos Panamericanos el año siguiente con el II mundial de fútbol que organizó el régimen fascista de Benito Mussolini en Roma (1934) o los Juegos Olímpicos que albergó el régimen nazi de Adolf Hitler en Berlín (1936).

\section{Mundo Deportivo: una revista deportiva al servicio del peronismo}

Mucho puede aprenderse de los valores y mensajes que intentaba transmitir el régimen mediante los deportes al recorrer las páginas del semanario Mundo Deportivo, que comenzó a publicarse en 1949 (Panella, 2015; Rodríguez y Añon, 2010). Poco antes, el gobierno había adquirido el 51\% de la compañía Haynes, una superpotencia de medios -en relación con los parámetros de la época- que editaba el diario El Mundo y toda una serie de periódicos populares (Sirven, 1984). Esta adquisición reflejaba el creciente autoritarismo del régimen. El año 1947 fue una separadora de aguas en las relaciones del gobierno peronista con el cuarto poder. Desde entonces, la tendencia fue claramente controlar y silenciar la mayor parte de los medios 
independientes o dificultar su tarea. A comienzos de aquel año, solo dos de los seis matutinos de la Capital Federal -Democracia y El Laborista- apoyaban a Perón, mientras que Clarín, La Nación, La Prensa y El Mundo se identificaban con posturas opositoras. Lo mismo regía para tres de los vespertinos: La Razón, Crítica y Noticias Gráficas. El único properonista era La Época. Al cabo de seis años, La Nación era el único de los diez que no se identificaba con el régimen. Uno tras otro, los demás periódicos capitalinos fueron sucumbiendo al control del régimen.

Antes de la mencionada transacción, la Editorial Haynes estaba controlada por capitales angloestadounidenses; ahora pasaba a convertirse en un canal por el que las autoridades diseminaban la ideología peronista a diversos segmentos de la opinión pública: mujeres, niños, adolescentes, aldeanos, círculos científicos y tecnológicos, fanáticos de los deportes, etc. Bajo la dirección de quien era considerado uno de los más estrechos colaboradores de Evita, Carlos Vicente Aloé $\underline{10}$, la editorial pugnó por alejar a los lectores de los semanarios que eran propiedad de Atlántida, la veterana editorial conservadora y católica que fundara Constancio Vigil en 1918 (Bontempo, 2012).

El más prominente de los semanarios infantiles era Billiken, que se publicaba desde 1919 (Brafman, 1992; Bontempo, 2012b). Ante la negativa de Atlántida de doblegarse ante el régimen, los peronistas intentaron desplazar a Billiken de su influyente posición con la aparición, en 1949, del semanario Mundo Infantil. Billiken no recuperó su liderazgo en el mercado de los periódicos para niños hasta la caída de Perón, en septiembre de 1955.

Los periódicos deportivos pasaron por un proceso similar. El Gráfico fue el principal semanario del ramo hasta que el peronismo llegó al poder. También se trataba de una publicación de Atlántida, que comenzó a editarse en 1918 (Archetti, 1995; Karush, 2003). Una vez más, el esfuerzo por suplantarlo supuso la creación de un semanario competidor en abril de 1949: Mundo Deportivo, más colorido y con más páginas. Llegó a obtener una circulación de 220.000 ejemplares (Aloé, 1969:248). Este era más o menos el mismo número de copias que distribuía el veterano El Gráfico (Eujenian, 1999:128).

Quien lea las notas de El Gráfico del período 1949-55 a duras penas se dará cuenta de que la Argentina estaba gobernada por el peronismo, aunque dicho movimiento dominaba numerosos aspectos de la cultura, los espectáculos y el deporte. En contadas ocasiones aparece la figura del presidente Perón, generalmente en notas o imágenes sin firma, como si hubiera sido plantada allí por el servicio de prensa del Estado.

En claro contraste, los ejemplares de Mundo Deportivo abundan en fotografías, artículos y demás que cantan loas al régimen, al liderazgo de Perón, a la jefa espiritual de la nación (Eva Perón) y a la política en favor de los deportes del gobierno. En este sentido, los artículos editoriales (que aparecían firmados por Carlos Aloé, (aunque es posible que hubieran sido redactados por alguien del personal) resultan especialmente significativos. Aloé era un apasionado de los deportes desde edad temprana y había practicado el fútbol y el boxeo (Aloé, 1969). Sus artículos editoriales utilizaban a menudo la metáfora de la nación como un equipo deportivo y predicaban los valores de la solidaridad y la cooperación, así como de la organización, la disciplina y la obediencia al líder de la sociedad; una sociedad jerárquica y organizada en la que cada uno conocía su puesto y la función que debía cumplir. Los editoriales más interesantes son los que se publicaron a comienzos de 1954, los cuales presentaban las explicaciones de un padre a su hijo sobre la esencia de los deportes:

Es un juego de conjunto, un esfuerzo común, mancomunado; es decir, tienes que sumar todas tus fuerzas a las de tus compañeros. Dentro del conjunto tú tienes una misión: la de defender, atacar o avanzar... observarás la belleza de la armonía... verás qué tremenda fuerza tiene así el esfuerzo colectivo... 
También te acostumbrarás a escuchar a un director técnico, que apreciará tu juego o te indicará lo que debes hacer, muchas veces aún contra tus propios deseos, contra tu propia voluntad. En eso encontrarás la disciplina tan indispensable, cuando se quiere triunfar. $\underline{11}$

\section{La inauguración de los Juegos Panamericanos}

El 25 de febrero de 1951 se inauguraron los I Juegos Panamericanos en la cancha de Racing Club, inaugurada pocos meses antes con el nombre "Estadio Presidente Perón” (Bernetti, 2015). La ceremonia oficial fue la coronación y el apogeo de un prolongado esfuerzo organizativo $\underline{12}$. En su discurso, el ministro de la Suprema Corte de Justicia y presidente de la CADCOA, el juez Rodolfo Valenzuela, atribuyó a Perón la iniciativa por este nuevo proyecto deportivo (Torres, 2011). $\frac{13}{}$ De hecho, la idea había sido concebida en septiembre de 1940 durante una conferencia de las organizaciones deportivas del continente (Daskal \& Sazbón, en prensa). Ya entonces se había decidido que la sede de los juegos sería Buenos Aires, mas la fecha originalmente establecida de 1942 fue postergada en dos oportunidades: la primera para 1948 debido a la guerra mundial y su reciente extensión al hemisferio occidental, y nuevamente para 1951 debido a los Juegos Olímpicos en Londres.

Paralelamente con su retórica antiestadounidense y sus retos a Washington en conferencias interamericanas, la Argentina peronista bregaba por el fortalecimiento del panamericanismo. El presidente insistía en afirmar

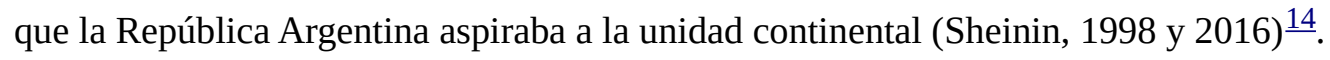

Supuestamente, los Juegos Panamericanos debían demostrar este compromiso argentino. El gobierno de Perón también quería que sirvieran como prueba internacional del éxito del régimen. Para lograr ambas metas, el líder instó a los organizadores a invertir todo esfuerzo posible y prometió también toda la asistencia financiera que pudiera necesitarse: "En eso no ahorraremos un centavo (...) Esas cosas se hacen bien del todo o no se hace nada (...) En una palabra, lo que quiero es dejar sentado que no nos fijaremos en economías”. También pidió a los atletas que entrenasen arduamente antes de los Juegos: "Todos sabemos que el deporte es hijo de la preparación. Cincuenta por ciento el hombre; y el cincuenta por ciento restante es lo que se capacita con la preparación y el entrenamiento” $\underline{15}$.

Coherentemente con esto, alrededor de un año y medio antes del inicio de los juegos, los esfuerzos de la organización se aceleraron. Dos meses antes de la ceremonia inaugural, la delegación argentina estableció su campo de entrenamiento en Ezeiza, cerca de la capital. Durante una sorpresiva visita al sitio, Perón habló con los atletas que se estaban preparando e inmediatamente antes del comienzo de las competencias envió a cada miembro de la delegación un telegrama de aliento y deseos de éxito (que se obtendría, según decía, con esfuerzo, fe y determinación). Para impulsar la moral de la delegación, veteranos con destacadas carreras internacionales también fueron de visita al campo de entrenamiento en Ezeiza, entre ellos los boxeadores Luis Ángel Firpo, Oscar Casanovas y Carmelo Ambrosio Robledo. $\underline{16}$

La década peronista fue testigo de una creciente tendencia autoritaria, a medida que el régimen restringía paulatinamente diversas libertades políticas y civiles. Simultáneamente crecía la presión sobre quienes representaban a la Argentina para que regresaran al país con medallas. Antes de los II Juegos Panamericanos que se celebraron en México en 1955, se exigió a los atletas que demostraran lealtad (un concepto con un fuerte significado en el peronismo de esos tiempos) y patriotismo mediante el esfuerzo y el sacrificio, ya que estaban llevando a cabo una misión nacional. Cualquier otra conducta sería considerada como una traición a la patria. En un editorial en Mundo Deportivo, Carlos Aloé escribió: 
En la Nueva Argentina obedecemos al espíritu invencible de realizar para la comunidad todo el bien que nuestra causa nos impone y nos obliga. Todos formamos parte de un gran equipo, al cual debemos, no solamente solidaridad y disciplina, sino también el más absoluto acatamiento a la idea de conquistar para nosotros un lugar de privilegio dentro de los pueblos civilizados de la tierra. Quien así no lo haga cometerá un acto de deslealtad hacia sus compañeros y hacia la patria. Cumplir con el deber de la hora es sagrada obligación, para lo cual no deben escatimarse esfuerzos ni sacrificios $\frac{17}{}$.

\section{La exhibición de las obras públicas del régimen}

El número especial de Mundo Deportivo le agradecía explícitamente al primer mandatario y a su esposa por su apoyo a los deportes en general y por posibilitar la realización de los I Juegos Panamericanos en particular. $\underline{18}$ En el artículo editorial, Aloé enfatizaba los vínculos entre deportes y modernidad, así como la iniciativa, la valentía y la tenacidad que caracterizan a las razas fuertes y a la Argentina de Perón; la vitalidad y el espíritu lozano con que la Nueva Argentina ofreció "con sus estadios y sus palestras el ejemplo de la fiesta del músculo en medio de esta humanidad alocada que corre ciega a su destrucción”1․

Pero el librillo destacaba no sólo los logros atléticos en los juegos, sino también las banderas ideológicas de justicia social, soberanía política y justicia económica que enarbolaba el régimen. Se prestaba especial atención a las obras públicas y a la nueva infraestructura construida por las autoridades peronistas, que incluía carreteras, puentes y la nacionalización de la red ferroviaria $\underline{20}$. Incluso la nueva flota mercante estatal recibió su espacio en las páginas de este número especial de la revista. Entre los proyectos ambiciosos de infraestructura emprendidos por el gobierno de Perón, uno de los más importantes fue la planificación, construcción e inauguración del aeropuerto de Ezeiza en 1949 y la habilitación de instalaciones deportivas, sanitarias y educativas en los alrededores (Ballent, 2002). También se construyeron barrios para trabajadores en las inmediaciones de lo que las autoridades argentinas describían como "el aeródromo más grande del mundo". $\underline{21}$ Bautizado con el nombre del general Juan Pistarini -quien fuera ministro de Obras Públicas durante casi una década, desde el golpe de estado de 1943 hasta 1952 (Ballent, 2013)-, el aeropuerto se encuentra a apenas $33 \mathrm{~km}$ de la Plaza de Mayo, donde está emplazada la Casa Rosada, el palacio presidencial. Hasta allí se podía llegar por la autopista Ricchieri, a una velocidad de $120 \mathrm{~km} / \mathrm{h}$ ”. No sorprende entonces que la Provincia de Buenos Aires (en cuya jurisdicción se encuentra la estación aérea) incluyera a Ezeiza en sus “excursiones justicialistas a las grandes obras de la Revolución” (Troncoso \& Lois, 2004:284).

Los visitantes extranjeros, supuestamente, debían asombrarse con los logros del gobierno en cuanto aterrizaran en este aeropuerto, que era la puerta de entrada a la Nueva Argentina de Perón. El número especial de Mundo Deportivo dedicaba varias páginas a las obras públicas monumentales del país, especialmente las de Ezeiza. El recorrido elegido para correr la maratón debía mostrar a todos cómo "Buenos Aires, la gran capital del sur, se abrió grandiosa, en un abrazo imponente a todos nuestros hermanos de América”르. Más de un millón de espectadores se agolparon a lo largo de los 42,195km de esa carrera, un número sin precedentes. $\underline{23}$ El ganador -como se esperaba- fue Delfo Cabrera, que poco menos de tres años antes había obtenido la medalla de oro olímpica en Londres. Sin embargo, no se pudo cumplir con el anhelo de ver a Cabrera superar el récord olímpico que había sido establecido en los Juegos de Berlín, en 1936. $\underline{24}$ 


\section{La futura generación de argentinos}

También los deportes femeninos gozaron de una promoción sin precedentes en la Argentina peronista. La delegación que participó en los Juegos Olímpicos de 1948 en Londres incluía diez mujeres atletas, mientras que en Berlín (1936) sólo una había representado al país. En el número especial de Mundo Deportivo al finalizar los Juegos Panamericanos de 1951, los temas de género fueron prominentes. Obviamente, gran cantidad de páginas se referían a Eva Perón como auspiciante de actividades deportivas, particularmente torneos infantiles, pero también se la elogiaba por su labor en relación con los derechos sociales y políticos de las mujeres (Barry, 2009). La publicación glorificaba los hogares de tránsito (casas temporarias para gente que necesitaba un lugar para vivir hasta que fueran resueltos sus problemas de vivienda o de empleo) que fueron establecidos para trabajadoras solteras. Uno de estos hogares -el que se encuentra en la calle Lafinur 298 y alberga hoy al museo Evita- sirvió como alojamiento para las mujeres atletas extranjeras que llegaron a Buenos Aires a competir en los Juegos Panamericanos. $\frac{25}{5}$

Según Brenda Elsey (2016:112), las atletas afroamericanas del equipo estadounidense apreciaron enormemente la cálida recepción que obtuvieron al llegar a la Argentina. De todos los equipos norteamericanos, el combinado femenino de atletismo era el más racialmente diverso e incluía a numerosas atletas del sur del país. Los argentinos alojaron a todas las atletas femeninas de la competición en la Fundación Eva Perón, sin tener en cuenta la política norteamericana de segregación racial del periodo. La encargada del equipo, Evelyn Hall, exmedallista olímpica en los Juegos de 1932, quedó muy agradecida con la actitud demostrada por los anfitriones argentinos.

La cobertura de las actividades deportivas femeninas fue muy amplia en esta revista. Cada número de Mundo Deportivo incluía informes de básquet, tenis, hockey, natación, vóley, ajedrez, waterpolo, golf, atletismo, etc., en sus vertientes con mujeres. El ya referido número especial tras los Juegos Panamericanos incluyó numerosas referencias a atletas argentinas como Ingeborg Mello de Preiss, y extranjeras como la mexicana Hortensia López García y la chilena Gate Lazo.

El régimen promovió los deportes nacionales, tanto en las "disciplinas de elite” como en las populares y masivas. En la carta que Mundo Deportivo publicó en el número especial tras los Juegos Panamericanos, Perón destaca por encima de todo la atención prestada al deporte infantil. Con el repetitivo slogan "En la Nueva Argentina los únicos privilegiados son los niños", el presidente se refería de hecho, a las competiciones deportivas infantiles organizadas por la Fundación Eva Perón. $\underline{26}$ Unas páginas más adelante se incluía el inevitable retrato de la primera dama, como líder espiritual que creó el campeonato infantil de fútbol. ${ }^{27}$ En la primera edición de dicho campeonato, en 1948, participaron aproximadamente 11.000 niños. Dos años después, el número superaba los 100.000. En la primera mitad de la década de 1950 se agregaron otras disciplinas y también se alentó la participación de las niñas. En vísperas del golpe militar que derrocó al régimen, más de 215.000 niños participaron en 10 deportes (Plotkin, 1993:275; Ross, 1988:280-281). En los eventos y las actividades patriotas que los acompañaban, los campeonatos se utilizaban como un medio para lograr la unidad y la uniformidad nacional. En uno de los primeros números del semanario Mundo Infantil se señalaba: "El Campeonato Evita hará el sueño de los maestros y de los gobernantes: unirá a la juventud argentina por sobre las divisiones locales aun sobre los límites provinciales: porque la voz del deporte es estentórea, potente y los vigoriza y electriza como una descarga. A su conjunto, todos se sentirán iguales, todos pensarán de la misma manera” (citado en Plotkin, 1993:278).

Los nombres de muchos de los equipos participantes en estos campeonatos también reflejaban el carácter nacional y/o peronista que los organizadores querían enfatizar: 'Malvinas Argentinas', 'Antártida Argentina', 'San Martín', 'Perón', 'Evita Lucero del Alba', '17 de Octubre' (en homenaje a la manifestación de trabajadores de aquel día de 1945, que se considera como el acto fundacional del movimiento justicialista), etc. Los 
partidos siempre eran precedidos por la entonación del Himno Nacional, mientras que el himno del campeonato era en sí una oda de elogios al matrimonio Perón.

\section{Pato - un deporte argentino}

El fútbol -el deporte más popular de la Argentina- atrajo más espectadores a los Juegos Panamericanos que cualquier otra disciplina. El número especial de Mundo Deportivo dedicó varias páginas a los principales estadios de fútbol de Buenos Aires, particularmente los de Racing, River Plate e Independiente. La revista destacaba que antes de la llegada de Perón al poder había en la región metropolitana un único estadio con tribunas de cemento y que a comienzos de la década de 1950 la Nueva Argentina estaba a la vanguardia del mundo en cuanto a estadios modernos para fútbol y la cantidad de espectadores que podían albergar (Gaffney, 2009). $\underline{28}$

Sin embargo, el fútbol, como casi todos los deportes que se practicaban en el país, era de origen extranjero y, en este caso, un juego importado desde Gran Bretaña. Tras décadas de influencia foránea, la Nueva Argentina de Perón deseaba ser considerada madura e independiente también en el aspecto atlético, además del político. En 1949, el líder conminó a diputados a establecer un sistema separado, nacional, con el siguiente argumento: "Nosotros tenemos una cocina argentina y no podemos acostumbrarnos a otra comida; tenemos una música que es nuestra. Así también debemos tener una gimnasia y un deporte adaptados a nuestro pueblo” (citado en Ganduglia, 1954:8-9).

Esta fue la base para que el comité organizador de los I Juegos Panamericanos decidiera presentar al pato, un juego ecuestre con similitudes al polo, como el deporte nacional. Los organizadores vieron los Juegos como una oportunidad para exponer ante el continente todo "este clásico deporte genuinamente criollo, cuya antigüedad práctica en nuestro suelo se remonta a centurias”르. El artículo dedicado al pato en Mundo Deportivo enfatizaba la idiosincrasia del gaucho (jinete nómada y vaquero de las Pampas). Dos años después, Perón instituyó formalmente al pato como deporte nacional mediante un decreto fechado el 16 de septiembre de 1953.

Mundo Deportivo también presentaba a todos los visitantes extranjeros al juego de pelota paleta como “deporte genuinamente nacional”, con raigambre en el período colonial hispánico. $\underline{30}$ Según la revista, este deporte ya se practicaba en Argentina en 1830 y Juan Manuel de Rosas -caudillo que por entonces gobernaba en Buenos Aires- ordenó a sus asesores que planificaran una instalación para jugar la pelota de paleta. En 1951 -si nos atenemos a lo afirmado por Mundo Deportivo- medio millón de conciudadanos lo practicaba.

\section{Conclusión}

Ante una muchedumbre que lo aclamaba durante la ceremonia de clausura de los I Juegos Panamericanos de 1951 en el estadio de River Plate, el presidente argentino repitió la misma idea que venía predicando desde hacía ya varios años respecto del deporte como una escuela de hombres sanos que luchan por la grandeza de su país $\underline{31}$. Perón no desaprovechó la oportunidad para enarbolar los tres estandartes de su movimiento: un país justo, libre y soberano. $\frac{32}{}$ Perón felicitó a los atletas argentinos por sus logros y estos a su vez dedicaron sus triunfos -como era habitual en la Nueva Argentina- al líder. Tras haber montado con éxito un espectáculo impresionante, la ceremonia de clausura encarnó lo que algunos consideraron como uno de los mejores momentos del peronismo. Refiriéndose con orgullo al gran número de medallas obtenidos por sus compatriotas, Mundo Deportivo escribió que el verdadero héroe de los juegos fue Honorio Rando, director de La Banda Monumental, ya que debió ejecutar con mucha frecuencia el himno nacional (cada vez que la Argentina ganaba una medalla) $\underline{\underline{33}}$. 
Algunos días después del cierre, Perón invitó a los atletas argentinos a la residencia presidencial. El máximo dirigente de la CADCOA, Rodolfo Valenzuela, elogió a los participantes diciendo: "Sé que en vuestro corazón (...) existe un intenso amor por esta Nueva Argentina de Perón y Evita”쓰.

¿Podía Perón sentirse satisfecho con los dividendos políticos que rindieron los juegos? Sólo en forma parcial. En el frente doméstico parecía que su popularidad aumentaba, incluso entre sectores de la oposición, gracias al entusiasmo generado por las victorias en la arena deportiva internacional $\frac{35}{}$. En varios países de habla hispana también hubo un aparente aprecio por la exitosa organización del evento. Pero si una de las metas al celebrar los juegos en Buenos Aires era mejorar la imagen del régimen en los Estados Unidos, entonces se puede afirmar que en este punto fue un rotundo fracaso $\frac{36}{}$. La cálida acogida dispensada a la delegación norteamericana influyó muy poco $\frac{37}{3}$. Esto se debe en parte a que los Juegos Panamericanos no suelen provocar mucho interés en ese país, y no nos referimos sólo a la primera edición de 1951. Pero en mayor medida, esto se debió a cuestiones políticas.

No importaba lo que Perón hiciera, no podía quitarse la mácula del apoyo que dio a la neutralidad de su país durante la Segunda Guerra Mundial. En los medios de comunicación estadounidenses fue siempre retratado como adherente a la Alemania nazi, un oficial militar autoritario que era también enemigo del capitalismo y del libre comercio (Quiroga, 2008). Unos artículos enviados por Milton Bracker, corresponsal del New York Times, ("Los Juegos Panamericanos sirven como una plataforma para exaltar la Nueva Argentina y su régimen”) y de Arthur Daley (“Hoy tenemos a Perón. Una década y media atrás era Hitler”) son testimonio de esta imagen $\underline{38}$. Bracker y su esposa, Virginia Lee Warren eran ambos periodistas veteranos que estuvieron cuatro años en Buenos Aires (1947-1951) y advertían constantemente sobre la caída de Argentina en el autoritarismo. La sombra de la confiscación del matutino La Prensa -de la familia Gainza Paz- y su cesión a la Confederación General del Trabajo (CGT) no podía borrarse con la organización exitosa de un evento deportivo internacional (Panella, 2008; Cane, 2011).

El régimen continuó su política en cuestiones deportivas. En vísperas de los Juegos Olímpicos de 1952 en Helsinki -programados originalmente para 1940 pero cancelados por la guerra- Aloé escribió en Mundo Deportivo que la Nueva Argentina había alcanzado un lugar prominente en la esfera deportiva tanto a nivel continental como mundial, y que por ello sus representantes en las competiciones internacionales adquirían una gran responsabilidad ante la nación $\underline{39}$.

Los Juegos Panamericanos debían, entre otras cosas, mostrar al Comité Olímpico Internacional (COI) que la Argentina de Perón podía ser la sede exitosa de una edición de los Juegos Olímpicos. Los organizadores del evento de 1951 en Buenos Aires hicieron cuanto hubo a su alcance para conferir un toque olímpico y celebraron la llegada de la tea olímpica sagrada desde Grecia. $\stackrel{40}{ }$ Los peronistas alimentaron la esperanza de que los finlandeses no alcanzaran a terminar los preparativos a tiempo y su país fuera elegido como sustituto. Buenos Aires casi fue seleccionada para albergar los juegos de 1956, pero perdió en la cuarta ronda por 2120 y ese honor correspondió a Melbourne (Torres, 2007). Argentina volvió a presentar su candidatura para la edición de 1960, pero en esa ocasión -junio de 1955- perdió por razones políticas obvias; el mismo mes que el COI debía tomar la decisión hubo un fallido golpe de estado para derrocar a Perón. A la luz de la inestabilidad política del país, Buenos Aires no parecía un sitio conveniente para llevar a cabo un torneo internacional de este tipo. 


\section{Notas}

1 Una versión anterior en inglés de este artículo se va a publicar bajo el título "Turning the Country into an 'Immense and Clamorous Stadium': Perón, the New Argentina, and the 1951 Pan-American Games", The International Journal of the History of Sport. Agradezco a Eliezer Nowodworski y Pablo Bornstein su ayuda en la preparación de este texto.

2 Algunos periodistas deportivos americanos mostraron su decepción cuando Argentina se puso por delante en el campeonato, describiéndolo como "uno de los días más negros en la ilustre historia del atletismo americano”. New York Times, 1 de marzo de 1951, p. 35.

$\underline{3}$ Mundo Deportivo No. 100, Edición especial, 'Primeros Juegos Deportivos Panamericanos' , 15 marzo de1951.

4 CADCOA, Memoria y balance general-inventario XXVI aniversario (Buenos Aires: n.p., 1947), 8-9. Entre finales de 1950 y mediados de 1951, la CADCOA recibió 10 millones de pesos de la Tesorería General de la Nación, con motivo de la celebración de los Juegos (Daskal \& Sazbón, en prensa) .

$\underline{5}$ El Gráfico, 25 de junio de 1948, p. 28.

6 La revista del club, River, subrayaba que su estadio Monumental era reconocido "una vez más por las autoridades superiores de nuestro deporte como uno de los mejores del continente sudamericano... con ello queda demostrado una vez más, la alta capacidad de River, no solo en el consenso nacional, sino internacional", ver River 7.9, No. 310, (1950), p. 5 y Rodrigo Daskal (2015).

Z 'Los dividendos del deporte', Primera Plana, 6 Septiembre de 1966, p. 41.

8 Carlos Aloé, 'Campeones Mundiales de Básquetbol', Mundo Deportivo 26, 9 de noviembre de 1950.

$\underline{9}$ Héctor Villita, 'Con su triunfo en el campeonato mundial, Argentina revolucionó las técnicas del básquetbol', Mundo Deportivo, 9 de noviembre de 1950, p. 63.

10 Jefe de Despacho de la Presidencia entre 1948 y 1952 para desempeñarse luego como gobernador de la provincia de Buenos Aires desde 1952 hasta el derrocamiento en 1955 (Panella, 2014; Rodríguez, 2007)

11 Carlos Aloé, 'Aprende, hijo', Mundo Deportivo 248 (14 [de enero de] 1954), p. 22.

12 Mundo Deportivo, Edición especial 'Primeros Juegos Deportivos Panamericanos' (15 de marzo de 1951), p. 26; New York Times, “Americas Games Opened by Perón”, 26 February, 1951

$\underline{13}$ 'Se inauguraron anoche los Juegos Panamericanos', La Nación (26 de febrero de 1951), p. 7.

14 Juan D. Perón, The Argentine International Policy (Buenos Aires: n.p., n.d), p.3.

15 Juan D. Perón, Delegados del deporte argentino escuchan a Perón (Buenos Aires: s/e, 1950), 4-6, 8. Ver también Carlos Aloé, 'Perspectivas para el Panamericano', Mundo Deportivo (12 [de octubre de] 1950), p. 26.

16 Mundo Deportivo (15 de marzo de 1951), p. 20.

17 Carlos Aloe, 'Los próximos Juegos Panamericanos', Mundo Deportivo 300 (13 de enero de 1955), 22.

$\underline{18}$ Ver también 'Agradecimientos al Jefe de Estado y a su esposa', La Nación (27 de febrero de 1951), 3.

19 Mundo Deportivo (15 de marzo de 1951), 3.

20 Mundo Deportivo (15 de marzo de 1951), 8, 173, 235, 237; Campeón (del deporte popular) (28 de febrero de 1951), 3. 
21 Ministerio de Obras Públicas, Administración General de Parques Nacionales y Turismo, Memoria general correspondiente al año 1949 (Buenos Aires: n.p., 1950), 160.

$\underline{22}$ Mundo Deportivo (15 de marzo de 1951), 8.

23 Mundo Deportivo (15 de marzo de 1951), p.126.

24 Mundo Deportivo (15 de marzo de 1951), p.128.

$\underline{25}$ Mundo Deportivo (15 de marzo de 1951), pp.24-25.

26 Mundo Deportivo (15 de marzo de 1951), 4.

$\underline{27}$ Mundo Deportivo (15 de marzo de 1951), 7.

28 Mundo Deportivo (15 de marzo de 1951), 32..

29 Mundo Deportivo (15 de marzo de 1951), 181.

30 Mundo Deportivo (15 de marzo de 1951), p.178.

31 Mundo Deportivo (15 de marzo de 1951), pp. 244-246.

$\underline{32}$ 'Clausuráronse ayer los Juegos Panamericanos', La Nación (10 de marzo de 1951), p. 1; Comité Olímpico Argentino, Primeros Juegos Deportivos Panamericanos (Buenos Aires: s.e., 1951).

$\underline{33}$ Carlos de la Braga, 'Nota de emoción', Mundo Deportivo (15 de marzo de 1951), p. 154.

$\underline{34}$ 'Celebróse el éxito de nuestro país en los Juegos Deportivos', La Nación (11 de marzo de 1951), p. 7.

$\underline{35}$ Ver, por ejemplo, 'Los juegos dejaron un saldo favorable', La Nación (10 de marzo de 1951), p. 3.

$\underline{36}$ Sobre la imagen de la Argentina peronista en los Estados Unidos, ver Margaret O'Donnell, 'How Time and Newsweek Covered the Argentine Story in 1947', Inter-American Economic Affairs (Summer 1948), pp. 315; I. G. Lewis, 'American Opinion of Argentina, 1939-1949' (tesis de master, Georgetown University, 1951).

37 Mundo Deportivo (15 de marzo de 1951), 62-63; La Cancha (27 de febrero de 1951), 12-13; El Gráfico (9 de marzo de 1951), pp. 62-63.

38 Milton Bracker, 'Peróns Make Hay on Olympic Meet', New York Times (29 de febrero de 1951), p. 6; Arthur Daley, 'At Home and Abroad', New York Times (27 February 1951), p. 44. Ver también Virginia Lee Warren, 'U.S. Aide at Games Chides Argentines', New York Times (5 March 1951), p. 14.

$\underline{39}$ 'Nuestra concurrencia a Helsinki', Mundo Deportivo (24 de abril de 1952), 26.

40 Mundo Deportivo (15 de marzo de 1951), 46.

\section{Bibliografía}

Aloé, C. (1969). Gobierno, proceso, conducta. Buenos Aires: Sudestada

Archetti, E.P. (1995). Estilo y virtudes masculinas en El Gráfico: la creación del imaginario del fútbol argentino. Desarrollo económico, 35 (139 ), 419-442.

Ballent, A. (2002). El peronismo y sus escenarios: la operación territorial de Ezeiza (1949-1955). Entrepasados. 22, 7-26.

Ballent, A. (2013). Juan Pistarini. Soldado, ingeniero, ministro: un constructor de paisajes políticos. En R. 
Rein \& C. Panella (eds). La segunda línea. Liderazgo peronista, 1945-1955 (pp. 289-312). Buenos Aires: Pueblo Heredero/ Universidad Nacional de Tres de Febrero.

Barry, C. (2009). Evita Capitana: el Partido Peronista Femenino 1949-1955. Buenos Aires: EDUNTREF.

Bernetti, J. (2015). El Cilindro de Avellaneda: el estadio más peronista. En R. Rein (ed.), La Cancha Peronista. Fútbol y política, 1946- 1955 (pp.183-191). Buenos Aires: Editorial de la Universidad de San Martín.

Bontempo, P. (2012a). Editorial Atlántida. Un continente de publicaciones, 1918-1936. Tesis doctoral inédita. Universidad de San Andrés.

Bontempo, P. (2012b). Los niños de Billiken. Las infancias en Buenos Aires en las primeras décadas de siglo XX. Anuario del Centro de Estudios Históricos Prof. Carlos S.A. Segreti 12, 205-221.

Brafman, C. (1992). Billiken: poder y consenso en la educación argentina (1919-1930). Todo es Historia, 298.

Cane, J. (2011). The Fourth Enemy: Journalism and Power in the Making of Peronist Argentina, 1930-1955. University Park, PA: The Pennsylvania State University Press.

Daskal, R. (2015). 'River Plate y el peronismo: todos unidos triunfaremos'. En R. Rein (ed.). La Cancha Peronista. fútbol y política, 1946- 1955 (pp.167-182). Buenos Aires: Editorial de la Universidad de San Martín.

Daskal, R. \& Sazbón, D. (en prensa). El deporte, entre centralización gubernamental y la búsqueda de preservación de su autonomía: el caso de la CADCOA. En R. Rein\&

C. Panella (comps.). En busca de la Comunidad Organizada: Organizaciones políticas, sociales y económicas del primer peronismo. Buenos Aires: Editorial de la Universidad de Tres de Febrero.

Elsey, B. (2016). Cultural Ambassadorship and the Pan-American Games of the 1950s. The International Journal of the History of Sports, 33, Nos. 1-2

Eujanian, A.C. (1999). Historia de las revistas argentinas, 1900-1950. La conquista del público. Buenos Aires: Asociación Argentina de Editores de Revistas.

Fernández Moores, E. (2010). Breve historia del deporte argentino. Buenos Aires: El Ateneo.

Frydenberg, J. (2011). Historia social del fútbol. Buenos Aires: Siglo XXI.

Gaffney, C.T. (2009). Temples of the Earthbound Gods: Stadiums in the Cultural Landscapes of Rio de Janeiro and Buenos Aires. Austin, TX: University of Texas Press.

Ganduglia, S (1954). El nuevo espíritu del deporte argentino. Buenos Aires: Presidencia de la Nación, Secretaría de Prensa y Difusión.

Karush, M.B. (2003). National Identity in the Sports Pages: Football and the Mass Media in 1920s Buenos Aires. The Americas 60, (1), pp. 11-32.

Panella, C. (2008). La expropiación del diario La Prensa: ataque a la libertad de prensa o acto revolucionario. En R. Rein \& C. Panella (eds). Peronismo y prensa escrita (pp. 131-165). La Plata: EDULP.

Panella, C. (2014). Carlos V. Aloé. Lealtad y administración. En R. Rein \& C. Panella (eds). La segunda línea. Liderazgo peronista (pp.11-28). Buenos Aires: Pueblo Heredero/UNTEF

Panella, C. (2015). Mundo Deportivo: la mirada peronista del deporte argentino. En R. Rein (ed.). La 
Cancha Peronista. Fútbol y política, 1946- 1955 (pp.47-64). Buenos Aires: Editorial de la Universidad de San Martín.

Plotkin, M. (1993). Mañana es San Perón: propaganda, rituales políticos y educación en el régimen peronista, 1946-1955. Buenos Aires: Editorial de la Universidad Nacional de Tres de Febrero.

Quiroga, N. (2008). Corresponsales, editorialistas, turistas. Las representaciones sobre el peronismo en el New York Times, 1946-1951. En R. Rein \& Caludio Panella (eds). Peronismo y prensa escrita (pp. 203-253). La Plata: EDULP.

Rein, R. (1993). The Franco-Perón Alliance: Relations between Spain and Argentina, 1946-1955. Pittsburgh: University of Pittsburgh Press.

Rein, R. (1998). El Primer Deportista: The Political Use and Abuse of Sports in Peronist Argentina. International Journal of the History of Sport 15 ( 2), pp. 54-76.

Rein, R. (1998). Peronismo, populismo y política. Buenos Aires: Editorial de Belgrano.

Rein, R. (2013). From Juan Perón to Hugo Chávez and Back: Populism Reconsidered. En M. Sznajder, L. Roniger \& C. Forment (eds). Shifting Frontiers of Citizenship: The Latin American Experience (pp. 289311). Boston: Brill.

Rein, R (ed.). (2015). La Cancha Peronista. fútbol y política, 1946- 1955. Buenos Aires: Editorial de la Universidad Nacional de San Martín.

Rodríguez III, E. (2011). Libro I de los juegos panamericanos, 1951 a 2011. Buenos Aires: Al Arco.

Rodríguez, M.G. \& Añon, V. (2010). Mundo Deportivo. El deporte en la grafía estatal. En C. Panella \& G. Korn (eds). Ideas y debates para la nueva Argentina. Revistas culturales y políticas del peronismo (pp. 229253). La Plata: Ediciones de Periodismo y Comunicación.

Rodríguez, R. (2007). Carlos Vicente Aloé: subordinación y valor. La Plata: Archivo Histórico.

Ross, P. (1988). Policy Formation and Implementation of Social Welfare in Peronist Argentina, 1943-1955. Tesis doctoral. Sidney: University of New South Wales.

Senén González, S. (1996). Perón y el deporte. Todo es Historia 345, pp. 8-20.

Scher A., Blanco, G. \& Búsico J. (eds). (2010). Deporte nacional. Dos siglos de historia. Buenos Aires: Emecé.

Sheinin, D. (1998). Searching for Authority: Pan Americanism, Diplomacy and Politics in United StatesArgentine Relations, 1910-1930. New Orleans: University Press of the South.

Sheinin, D. (2006). Argentina and the United States: An Alliance Contained. Athens, GA: University of Georgia Press.

Sirven, P. (2012). Perón y los medios de comunicación (1943-1955). Buenos Aires: Sudamericana.

Torres, C. R. (2001). Tribulations and Achievements: The Early History of Olympism in Argentina, International Journal of the History of Sport 18 (3), pp. 59-62.

Torres, C. R. (2007). Stymied Expectations: Buenos Aires. Persistent Efforts to Host Olympic Games. Olympika: The International Journal of Olympic Studies 16. pp. 43-75.

Torres C. R. (2011). The Limits of Pan-Americanism: The Case of the Failed 1942 Pan-American Games. 
The International Journal of the History of Sport 28, (17), pp. 2547-2574.

Torres C. R. (2014). Peronism, International Sport, and Diplomacy. En L. Heather Dichter \& L.J. Andrew (eds). Diplomatic games: sport, statecraft, and international relations since 1945 (pp. 151-182). Lexington: University Press of Kentucky.

Troncoso, C. \& Lois, C. (2004). Políticas turísticas y peronismo. Los atractivos turísticos promocionados en Visión de Argentina (1950). Pasos 2 ( 2), pp. 281-294. 